\title{
Ovulation in Black Bengal nanny goats
}

\author{
V. H. Rao and N. K. Bhattacharyya \\ Division of Physiology and Climatology, Indian Veterinary Research Institute, Izatnagar, U.P., \\ India
}

Summary. Normally cycling primiparous Black Bengal nannies were studied by laparotomy at 8-h intervals between 24 and $48 \mathrm{~h}$ after the onset of oestrus. The ovulation rate was 4.00 and ovulation occurred between 32 and $48 \mathrm{~h}$ after the onset of oestrus. The activity in the two ovaries was equal.

\section{Introduction}

For the most meaningful utilization of an artificial insemination technique in goats, it is essential to know the characteristics and sequence of ovulation in the particular breed. The Black Bengal breed of goat (Capra hircus) is common in Bengal, Bihar and Orissa states of India. Direct information on ovulation in these dwarf but prolific nannies is meagre, although some indirect data on ovulation characteristics have been given by Ali, Hoque \& Hasanth (1973). We have therefore studied the characteristics and sequence of ovulation in these goats.

\section{Materials and Methods}

The nannies were 18-24 months old and had been bred on the experimental farm at the Indian Veterinary Research Institute, Izatnagar. All 20 had littered once and were exhibiting regular oestrous cycles. Separated from bucks, the animals were housed in clean sheds and fed a concentrate mixture (about $15 \mathrm{~g} / \mathrm{kg}$ body weight/day) and green chopped fodder (oat, maize or berseem) with wheat straw (1:1) and water ad libitum.

Vasectomized goats were run with the flock under supervision at 8-h intervals to detect the onset and cessation of oestrus.

Five of the nannies were subjected to laparotomy at $24,32,40$ and $48 \mathrm{~h}$ after the onset of oestrus during October (monthly means of temperature and vapour pressure $25.8^{\circ} \mathrm{C} ; 18.2$ $\mathrm{mmHg}$ ) and November (monthly means $21.3^{\circ} \mathrm{C} ; 12.2 \mathrm{mmHg}$ ). The puncture was at the site of the right sub-lumbar fossa and local anaesthesia (Planocaine 4\% w/v; M\&B India (P) Ltd.) was used.

The follicles in the ovaries were distinguished and counted as small (1-2 $\mathrm{mm}$ in diameter), medium ( $3-5 \mathrm{~mm}$ ), preovulatory ( $\geqslant 6 \mathrm{~mm}$ ), and ovulated (ruptured follicles).

The relative performance of the right and left ovaries was assessed by $\chi^{2}$ tests and various interactions were compared by analysis of variance according to the methods described by Snedecor \& Cochran (1968).

\section{Results and Discussion}

The rupture sites of the Graafian follicles were characterized by a fossa with a cherry red or blood-oozing spot which was slightly elevated from the surface. All the nannies showed ovulations at 32,40 and $48 \mathrm{~h}$ after onset of oestrus but the maximum number of follicles 
ovulating was found only at $48 \mathrm{~h}$, being about $50 \%$ at $32 \mathrm{~h}$ and $80 \%$ at $40 \mathrm{~h}$. As shown in Table 1 , the number of medium-sized Graafian follicles steadily increased between 24 and $48 \mathrm{~h}$ after the onset of oestrus while the number of small follicles remained fairly constant. A decrease in the number of preovulatory follicles correlated with an increase of those which had ovulated. Most ovulations had occurred by $48 \mathrm{~h}$ after oestrus. The type $\times$ hour interactions was significant $(P<0.01)$.

Table 1. Counts (mean \pm s.e.m.) of the different types of Graafian follicles in Black Bengal nannies after the onset of oestrus ( 5 animals at each time)

\begin{tabular}{|c|c|c|c|c|}
\hline \multirow[b]{2}{*}{ Graafian follicles } & \multicolumn{4}{|c|}{ Time after onset of oestrus (h) } \\
\hline & 24 & 32 & 40 & 48 \\
\hline \multicolumn{5}{|l|}{ Small $(1-2 \mathrm{~mm})$} \\
\hline Total & 53 & 44 & 54 & 52 \\
\hline Per nanny & $10.60 \pm 0.73$ & $8.80 \pm 0.77$ & $10 \cdot 80 \pm 1 \cdot 38$ & $10.40 \pm 0.98$ \\
\hline \multicolumn{5}{|l|}{ Medium (3-5 mm) } \\
\hline Total & 37 & 50 & 58 & 73 \\
\hline Per nanny & $7 \cdot 40 \pm 1 \cdot 14$ & $10.00 \pm 1.22$ & $11.60 \pm 0.78$ & $14.60 \pm 1.39$ \\
\hline \multicolumn{5}{|l|}{ Preovulatory $(\geqslant 6 \mathrm{~mm})$} \\
\hline Total & 9 & 16 & 17 & 1 \\
\hline Per nanny & $1.80 \pm 0.27$ & $3.20 \pm 0.43$ & $3.40 \pm 0.45$ & $0.20 \pm 0.00$ \\
\hline \multicolumn{5}{|l|}{ Ovulated } \\
\hline Total & 0 & 11 & 17 & 20 \\
\hline Per nanny & 0 & $2 \cdot 20 \pm 0.62$ & $3.40 \pm 0.28$ & $4 \cdot 00 \pm 0 \cdot 20$ \\
\hline
\end{tabular}

In this study, follicles less than $1 \mathrm{~mm}$ in diameter could not be conveniently counted at laparoscopy, but it can be assumed that such follicles were continuously growing for transfer to the pool of small follicles which remained constant. According to Pretorius (1971), further development of Graafian follicles in goats temporarily ceases between Days 12 and 18 of the oestrous cycle (Day $1=$ day of oestrus) and these quiescent Graafian follicles then develop quickly during pro-oestrus and oestrus of the next cycle. Most of the medium-sized Graafian follicles present in one oestrous cycle presumably develop and rupture early in the next cycle in polytocous breeds of goats (Bhattacharyya \& Prasad, 1974).

From the ovulation counts at $48 \mathrm{~h}$ after the onset of oestrus (4.00), it is obvious that the nannies of the Black Bengal breed have an ovulation rate higher than that known in any other caprine; 1.20 in Angora nannies (Shelton, 1960), 1.07 in non-descript Indian goats (Basu, Goswami \& De, 1961), 1.28 in Norwegian goats (Lyngset, 1968) and 1.43 in Barbari nannies (Bhattacharyya \& Prasad, 1974).

Both the ovaries appear to take part equally in the process of reproduction in Black Bengal nannies $\left(\chi^{2}=1.98\right.$; not significant), as they do in goats of the Barbari breed (Prasad, Das \& Bhattacharyya, 1979). The published evidence for monotocous breeds of goats is, however, in favour of greater activity in the right ovary (Lyngset, 1968; Achutankutty \& Raja, 1971).

Nalbandov (1964) suggested that ovulation in the goat occurred between 9 and $19 \mathrm{~h}$, and Salama (1972) reported that in local Egyptian goats ovulation occurred at about $27 \mathrm{~h}$ after onset of oestrus. Bhattacharyya \& Prasad (1974) found that only $23.4 \%$ of ovulations took place at $20 \mathrm{~h}$ after onset of oestrus in nulliparous Barbari nannies.

A high ovulation rate is considered to be an important characteristic, as shown by the result of selection of sheep with this trait in recent years in Australia and New Zealand (Bindon \& Piper, 1977). Pashmina goats in India rarely produce twins. Since the heritability of the multiple birth trait is high (Bindon \& Piper, 1977), it is possible that the high ovulation rate of the Black Bengal breed can be incorporated into monotocous breeds of goats which are bred for their hair and undercoat. 
We thank Dr C. M. Singh, Director, Indian Veterinary Research Institute, Izatnagar, for providing the necessary facilities.

\section{References}

Achutankutty, A. \& Raja, C.K.S.V. (1971) Studies on the incidence of early embryonic loss in goats based on abattoir specimen. Kerala vet. J. 2, 13-18.

Ali, S.J., Hoque, M.M. \& Hasanth, M.A. (1973) A study on growth and reproductive performance of Black Bengal goats under farm conditions. Ind. vet. J. 50 , 438-440.

Basu, S., Goswami, S.K. \& De, S.K. (1961) Studies on the genitalia of the goat. Ind. vet. J. 38, 302-304.

Bhattacharyya, N.K. \& Prasad, S.P. (1974) Ovulation characteristics in nullipara Barbari nannies. Proc. 26th Int. Congr. Physiol. Sci., New Delhi, 11, 392.

Bindon, B.M. \& Piper, L.R. (1977) Ovulation rate-its significance in selection for reproductive rate in sheep. Proc. 3rd Int. Congr. SABRO 10, $7 p$.

Lyngset, $O$. (1968) Studies on the reproduction in goat. III. Functional activity of the ovaries. Acta vet. scand. 9, 268-272.
Nalbandov, A.V. (1964) Reproductive Physiology, 2nd edn. W. H. Freeman and Co., San Francisco.

Prasad, S.P., Das, S.C. \& Bhattacharyya, N.K. (1979) A study on the characteristics of Graafian follicles and ovulation sequences in nullipara Barbari nannies. Ind. J. Anim. Sci. 49 (In press).

Pretorius, P.S. (1971) Gross ovarian changes in the cycling and anoestrous Angora does. S. Afr. J. Anim. Sci. 1, 63-66.

Salama, A. (1972) Ovarian changes in goats during oestrus. Ind. J. Anim. Sci. 42, 436-438.

Shelton, M. (1960) Influence of the presence of a male goat on the initiation of estrous cycling and ovulation. J. Anim. Sci. 19, 368-375.

Snedecor, G.W. \& Cochran, W.G. (1968) Statistical Methods, Indian edn. Oxford and IBH Publishing Company, Calcutta.

Received 5 March 1979 